\title{
Electrochemical Determination of Chemical Oxygen Demand in Mixed Organic Solution by $\mathrm{Al} / \mathrm{SnO}_{2}-\mathrm{TiO}_{2}$ Electrode
}

\author{
Xiaojiao Li ${ }^{1,2}$, Yan Shang ${ }^{3}$, Carlos Fernandez ${ }^{4}$, Tingting Pei ${ }^{1}$, Linshan Wang ${ }^{1, *}$ \\ ${ }^{1}$ College of Sciences, Northeastern University, Shenyang 110819, P.R. China. \\ ${ }^{2}$ School of Materials Science and Engineering, Northeastern University, Shenyang 110819, P.R. \\ China. \\ ${ }^{3}$ Chemical Experiment Center, Department of Basic Science, JilinJianzhu University, Changchun \\ 130118, P.R. China. \\ ${ }^{4}$ School of Pharmacy and Life Sciences, Robert Gordon University, AB107GJ, Aberdeen, UK. \\ *E-mail: 1swang@mail.neu.edu.cn
}

Received: 9 August 2021 / Accepted: 10 September 2021 / Published: 10 October 2021

Chemical oxygen demand (COD) is one of the most significant parameters in water-quality analysis, such as wastewater effluent monitoring. However, COD determination faces challenges of long measuring time and the use of toxic substances. In this work, an $\mathrm{Al} / \mathrm{SnO}_{2}-\mathrm{TiO}_{2}$ composite film electrode was prepared using the sol-gel method and dip-coating method for electrochemical determination of COD. The electrocatalytic reaction kinetics of the different organic substances on the electrode was studied in a three-electrode system. It was observed that the electrocatalytic reactions of all tested organic compounds on the $\mathrm{Al} / \mathrm{SnO}_{2}-\mathrm{TiO}_{2}$ electrode fitted the first-order kinetics. Based on the reaction rate constants at different temperatures, the activation energies for electrocatalytic oxidations of methylene blue and rhodamine B were $9.92 \mathrm{~kJ} / \mathrm{mol}$ and $14.7 \mathrm{~kJ} / \mathrm{mol}$, respectively. It was confirmed that dynamic behaviors of different organic substances on the electrode surface were different from each other. In addition, seven single-component organic solutions, four two-component organic solutions, and three three-component organic solutions were selected as the target standard solutions for the COD measurement experiments. Initial working currents measured by chronocoulometry were taken as the index of the value of COD of the target solutions within the operating voltage range of $1.5 \sim 3.5 \mathrm{~V}$ (vs. $\mathrm{SCE}$ ). In the range of $20 \sim 100 \mathrm{mg} / \mathrm{L}$, COD values of either single-component or multiple-component solutions were linearly related to the initial working currents. For solutions composed of different organic compounds with the identical COD concentration, each of their initial working currents was different from the others and increased with the working voltage. It could be concluded that the initial working currents measured by chronocoulometry was depended on COD concentration, applied voltage, as well as the composition of the tested solutions. By comparing the COD measurement results, using potassium hydrogen phthalate solution as the simulated wastewater, of the presented method with those of the standard potassium dichromate method, the accuracy and reproducibility of this method had also been approved. Therefore, we report a simple, rapid, and environmentally friendly COD determination method using an $\mathrm{Al} / \mathrm{SnO}_{2}-\mathrm{TiO}_{2}$ electrode, which is feasible for single- and multiple-component organic solutions. 
Keywords: Chemical oxygen demand; Electrochemical method; Multi-component solution; $\mathrm{Al} / \mathrm{SnO}_{2}-$ $\mathrm{TiO}_{2}$ electrode

\section{FULL TEXT}

(C) 2021 The Authors. Published by ESG (www.electrochemsci.org). This article is an open access article distributed under the terms and conditions of the Creative Commons Attribution license (http://creativecommons.org/licenses/by/4.0/). 